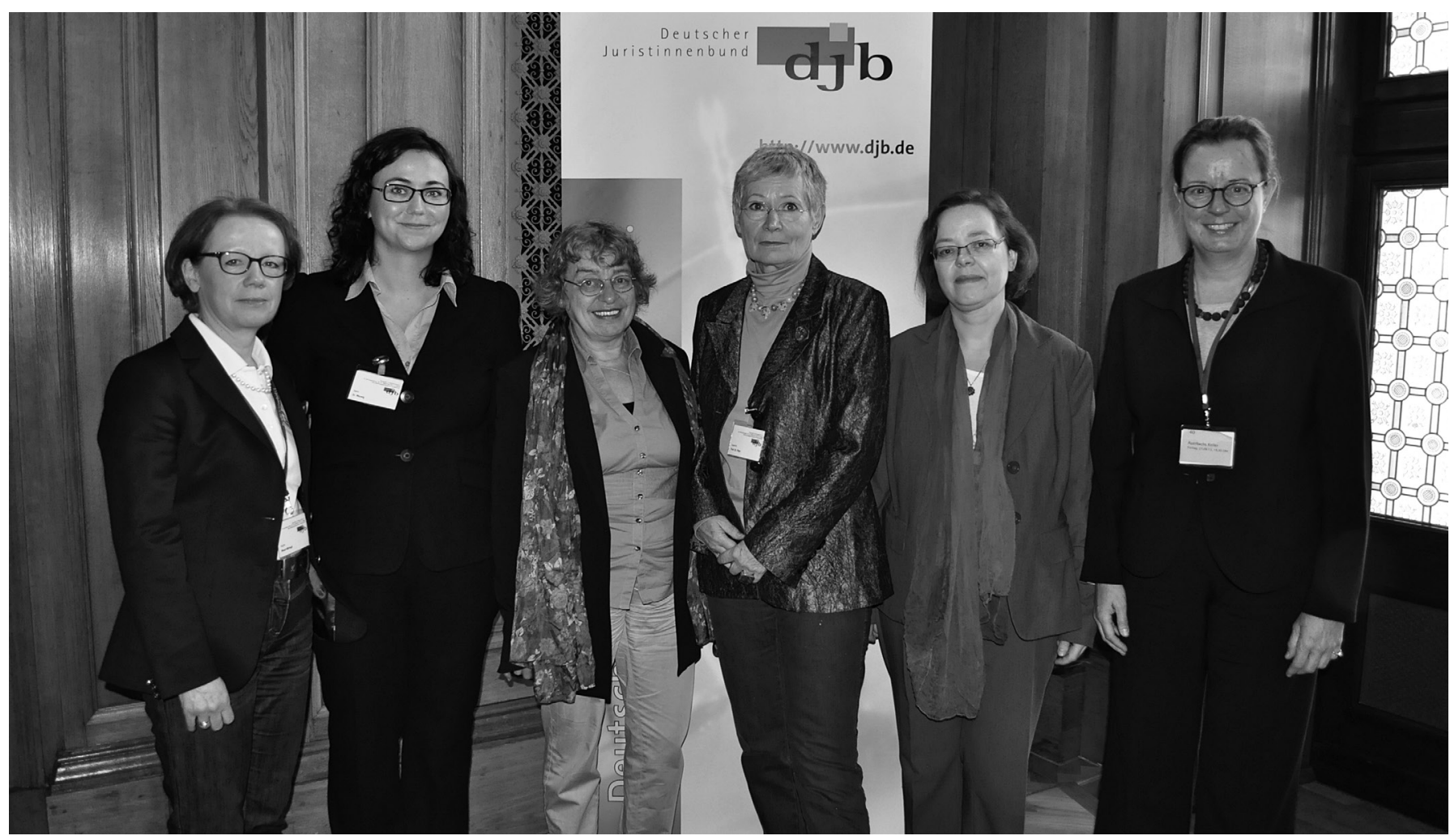

A Die fünf Podiumsteilnehmerinnen, die am Nachmittag zu Kommissionsvorsitzenden und damit in den Bundesvorstand gewählt wurden, mit ihrer Moderatorin am Samstagvormittag (v.l.n.r.): Brigitte Meyer-Wehage (Direktorin des AG, Brake, Vorsitzende der Kommission Zivil-, Familien- und Erbrecht, Recht anderer Lebensgemeinschaften), Dr. Maria Wersig (Berlin, Vorsitzende der Kommission Recht der sozialen Sicherung, Familienlastenausgleich), Dagmar Freudenberg (Staatsanwältin, Leiterin der Fachstelle Opferschutz im Landespräventionsrat Niedersachsen, Hannover, Vorsitzende der Kommission Strafrecht), Prof. Dr. Heide Pfarr (Kassel, Vorsitzende der Kommission Arbeits-, Gleichstellungs- und Wirtschaftsrecht), Maren Thomsen (Moderatorin der Podiumsdiskussion, Richterin am Bundesverwaltungsgericht, Leipzig, Vorsitzende der Kommission Öffentliches Recht, Europa- und Völkerrecht 2001-2005), Sabine Overkämping (Ministerialrätin, Ministerium für Justiz und Gleichstellung des Landes Sachsen-Anhalt, Magdeburg, Vorsitzende der Kommission Öffentliches Recht, Europa- und Völkerrecht).

Die Delegation zur European Women Lawyers Association - EWLA und der Deutschen Stiftung für internationale Zusammenarbeit - IRZ-Stiftung, die in den beiden vergangenen Jahren von Katharina Wolf respektive Daniela Giannone wahrgenommen wurden, wird in der folgenden Amtsperiode aus Praktikabilitätsgründen vom Präsidium übernommen.

Zum Schluss der sehr angenehmen und konstruktiven Mitgliederversammlung wurde der Ort des nächsten Bundeskongresses festgelegt: Der 41. Bundeskongress des djb wird vom 24. bis 27. September 2015 in Münster stattfinden.
Allen unseren Mitgliedern, die sich in den beiden vergangenen Jahren engagiert und tatkräftig und/oder durch ihre Beitragszahlung für unser Verbandsziel der Gleichberechtigung und Gleichstellung der Frau eingesetzt haben, danke ich herzlich. Ich danke auch all jenen, die durch ihre Unterstützung zum Gelingen des 40. Bundeskongresses beigetragen haben.

Ramona Pisal Präsidentin

\title{
Herzlichen Dank den Patinnen!
}

Die Spenden anderer Mitglieder ermöglichten es den „Jungen Juristinnen“ auch in diesem Jahr an dem 40. Kongress des djb und der Mitgliederversammlung in Leipzig teilzunehmen. Auf diesem Weg möchten wir den Patinnen ein herzliches Dankeschön für ihre Unterstützung aussprechen. Für uns „Junge Juristinnen“ ist der Austausch mit erfahrenen Kolleginnen und das Netzwerken unter Frauen sehr bereichernd. Wir möchten uns auch für die Bereitschaft der Kolleginnen bedanken, auf unsere vielen Fragen einzugehen und uns bei der Karriereplanung unterstützend zur Seite zu stehen.

Stellvertretend für alle „Jungen Juristinnen“:

Leonie Babst, Denise Cordes,

im Bundesvorstand zuständig für Mitglieder in Ausbildung 